\title{
Defining Fair Use on YouTube: A Guide to Modern Copyright
}

\author{
Cole Scott ${ }^{1}$ and John Murnan*
}

${ }^{1}$ Etowah High School, Woodstock, GA, USA

\#Advisor

\section{$\underline{\text { ABSTRACT }}$}

Copyright law is a large, complex issue that has found itself at the center of controversy on YouTube. Much of the debate around copyright centers on whether a video is fair use, the exception to copyright laws. There are large problems on YouTube surrounding the exploitation of the Content ID system, and the solutions to these problems often rely on the assumption of clear and defined copyright law, which is far from the case. This led my research into finding out based on the case law, what constitutes fair use on YouTube? Using a content analysis, these complexities of copyright law were able to be broken down into easy-to-understand guidelines. To do this, roughly 30 cases were found using the websites case.law and copyright.gov, and the decision of the case and the reasoning behind it were pulled out to create guidelines based on the copyright case law of court decisions. These guidelines consist of having a license for the copyrighted content, using the content for education, criticism or review, providing significant commentary to shift the focus away from the content, using the content for parody, changing the purpose of the content, or using an insignificant portion of the content. If any of these scenarios are met, then the video will likely not violate copyright. The use of these guidelines could be implemented into YouTubes algorithm, but more likely these guidelines would be easy to follow for creators to know whether or not their video will violate copyright.

\section{Introduction}

Copyrighted intellectual property is found widely across the internet repurposed and reused for entertainment in potentially infringing ways. Copyright laws protect intellectual property by legally granting creators a monopoly over their creative work providing an incentive for the artists to continue to create new content without the risk of losing potential revenue from others reproducing or "stealing" their work. Although the purpose of copyright is to promote creative content and innovation, it can have the adverse effect when copyright laws prevent the innovative use of others' original work in a new and creative way. An example of this creative use is Van Gogh's depiction of Haixia Liu's work in his painting The Café Terrace at Night which reworks past art in a new and unique way. The debate over using copyrighted work extends further on online platforms like YouTube where creators have made entire genres off of copyrighted content and are profiting in immense amounts from using other people's work.

Many creators have started businesses creating content for YouTube by making money through the advertisements placed on the videos. Having a content library that is so expansive and continually growing, it is inevitable that a significant amount of regularly published content would violate copyright. YouTube, however, has taken extensive steps to prevent copyrighted material from being uploaded. These preventative steps can often harm creators using content that is considered fair use. Copyright law defines fair use as "reproduction for purposes such as criticism, comment, news reporting, teaching (including multiple copies for classroom use), scholarship, or research, is not an infringement of copyright." The following factors must be consulted when determining whether the use of copyrighted material classifies as being fair: (1) the purpose and character of the use, including whether such use is of a commercial nature or is for nonprofit, educational purposes; (2) the nature of the copyrighted work; (3) the amount and substantiality of the portion used in relation to the copyrighted work as a whole; and (4) the effect of the use upon the potential 
market for or value of the copyrighted work (“17 U.S. Code $§ 107$ - Limitations on exclusive rights: Fair ..."). Because there is so much grey area in determining fair use and such a large market of entertainment relies on fair use on the internet, it becomes very important to define guidelines for fair use policies on the internet and YouTube in particular.

\section{Literature Review}

On YouTube there is much debate over use of copyrighted material and the methods which YouTube handles the use of copyrighted work on their site. Content ID, YouTube's primary method of handling copyrighted material on their website, works by storing a large database of copyrighted works provided by large copyright holders like Disney. When a video is uploaded to YouTube, the content of the video is scanned through Content ID to identify matches between the content within the video and the database. If any of the content within the video matches the database, the video will be flagged (Bartholomew, 2015). The owners of the copyrighted work can then choose to take the video down, keep the video up, or run advertisements on the video to receive revenue. Content uploaders can then dispute the copyright claim but disputing the claim can often take a lot of time from the creator's schedule. In addition, large corporations often have most of the power within the dispute and can threaten to go to court which would be too expensive for many small creators (Bartholomew, 2015). Content ID works very well when full, copyrighted works, like an episode to a TV show, are uploaded directly to YouTube, but the more complex uses of copyrighted works are too much for the algorithm to handle.

Bartholomew discusses that the main problem with Content ID is that it is unable to account for fair use within a video. Content ID was designed to keep YouTube from being sued for hosting infringing content. Because of this fact, Content ID is designed to automatically assume all use of copyrighted works are infringing. Bartholomew furthers that Content ID can harm creators because during disputes the money gained from advertisements is held by YouTube until the dispute is resolved. Many content creators base their entire income off of the money received from YouTube, and the money being held can put significant strain on creators (Bartholomew, 2015). Solomon agrees with Bartholomew on the power dynamic favoring large corporations through Content ID as well as that Content ID needs to better identify fair use. Solomon describes that as a result in the decision of the case Lenz v. Universal Music Corp., copyright holders must consider fair use before requesting a takedown notice. If the decision of this case was upheld, then many of the problems facing Content ID would become obsolete; however, as a result of the inconvenience and difficulty it would require to check for the corresponding criteria for fair use in every piece of potentially infringing material on YouTube, the decision of the Lenz case has not been consistently applied and all of the issues surrounding copyright and fair use continue to exist. Solomon argues that the corporations "bully" creators because they are scared to go into a lawsuit against the copyright holders.

Worsened by the fact that a single flag can result in lost revenues for the creator, due to the incompetence of Content ID's system, no matter how small of a part the infringing content is in the video, the copyright holder will receive all of the revenue from the video without taking into account the proportion of the video that is original work - an important factor to consider in determining fair use classification. This puts creators at a significant disadvantage as all of the reward for their creative work goes directly to the pockets of large corporations thanks to only a small portion of infringing content (Solomon, 2015). Marfo furthers the discussion of the power imbalance between creators and copyright holders when discussing the Nintendo Creators Program. This program allows creators to use Nintendo's content for videos in exchange for a portion of advertising revenue from all videos being directly given to Nintendo (Marfo, 2019). Marfo dislikes this approach because videos that are potentially fair use are still subject to the financial demands of this program that give revenue to Nintendo for non-infringing content. Bartholomew and Solomon would likely dislike Nintendo's program based on what they have discussed in their research because it discounts the possibility that any fair use exists. Solomon would also likely argue many creators would be too scared to use Nintendo's content without joining the program, even if fair use exists, because of how powerful Nintendo is and their ability to copyright claim a video and hold advertising revenue during the claim, as Bartholomew discusses, 
making it simply easier to join the predatory program. Programs like the Nintendo Creators' Program display the larger issue of the power dynamic in YouTube's copyright system.

Guzman (2015) agrees that creators being targeted for copyright even if fair use exists is a major problem. OCILLA (Online Copyright Infringement Liability Limitation Act) is a part of the Digital Millennium Copyright Act and was created to target the providers of a service like YouTube and have them take down any alleged copyright infringement. The act claims that the targets need to be done in "good faith"; however, this does not seem to be the case in practice as this act seemingly encourages providers to shoot first and ask questions later regarding fair use. The purpose of the act is to hold the providers accountable for the copyright infringement so that copyright holders would not have to track down individuals; instead, they would simply have to ask the provider to take down the content assuming they had all the appropriate paperwork (Guzman, 2015). Brown (2008) discusses the ramifications of OCILLA and the lack of liability that YouTube faces regarding hosting potentially copyright infringing content on their website. Many skeptics see YouTube as benefiting from infringing content on their website, comparing YouTube to sites like Napster; Brown argues, however, that YouTube tries with great zeal to eliminate any potentially infringing content from their website. As YouTube tries to remove this copyrighted content, they are protected from being found guilty of secondary infringement for benefiting from having copyrighted content on their website. Because YouTube wants to maintain the protection from being sued, they are more likely to flag any amount of infringing content regardless of fair use (Brown, 2008). Guzman continues this discussion of potential repercussions of OCILLA and how the copyright holders have a large amount of power when discussing the potential for fair use. Copyright takedowns largely go unchecked making it the creator's responsibility to show fair use in court rather than the copyright holders looking for potential fair use before blanket DMCA takedowns (Guzman, 2015). The inability for copyright holders to monitor for fair use highlights the intensity of the problem, as Solomon states, a direct betrayal of the precedent set by Lenz v. Universal Music Corp.

There are many solutions to solving the problem of Content ID and the lack of fair use on YouTube, but all of them center around the idea of clear guidelines on what constitutes fair use. There is no bright line standard when discussing fair use, and especially with a large power dynamic it becomes much more difficult for small content creators to know when their use is fair or when it is not. Most cases will need to go to court in order to decide fair use because of the blurred line between fair use and copyright infringement. Therefore, because all the solutions to fixing Content ID rely on a bright line standard for what constitutes fair use, I decided to look at the case law in order to determine a set of rules for the solutions of the literature to be based upon, leading me to my question: based on the case law, what constitutes fair use on YouTube?

\section{Methodology}

I decided to use a content analysis approach because it was the only way to formulate a list of guidelines for creators on YouTube to follow. Copyright is first and foremost a legal system so analyzing what the courts have determined would give the best insight to what is fair use under the law. In choosing this method, I analyzed roughly 30 court cases related to copyright and fair use from courts in the United States. After analyzing the court decisions, I determined how the precedent could then be applied to YouTube. Many of the court findings did not directly relate to YouTube; however, if the issues discussed were related, then I would apply the decision to YouTube content creation. In order to obtain the court cases used for my research, I used the websites case.law and copyright.gov. In my selection of cases, the ones I chose to include involved situations that are common to YouTube so the ruling could be applicable when creating guidelines to YouTube's incomplete system. These cases came from disputes on YouTube and elsewhere, like on television, in order to apply a wider range of standards for bright line guidelines to be based upon. In filtering court cases for the content analysis, I decided to exclusively use court cases that related specifically to direct copy and pasting of another's work in a way that could be considered fair use rather than focusing on the use of another's intellectual property in a more broad sense. To exemplify this, I used the case of SOFA Entertainment, Inc. v. Dodger Productions, Inc. which involved the use of a clip from the Ed Sullivan Show in a documentary about The 
Four Seasons. Even though the case involved content on television, the use of a clip to exemplify a point in a video is a common trait on YouTube and was therefore relevant to my research. An example of a case that I excluded was Teller v. Dogge. The case involves the portrayal of one of Teller's (of Penn \& Teller) magic tricks by Dogge on YouTube in an attempt to sell his course explaining how to do the trick. Even though the court case involved a situation on YouTube, because the case involved the reproduction of choreography rather than direct showing of copyrighted content, it was not relevant to my research and therefore not used.

After obtaining my cases, I saved usable cases to a spreadsheet and identified the main themes of the cases for purposes of comparison. I identified thematic categories consisting of type of content (video, pictures, or music), location (television, YouTube, internet), decision of the case, and whether the case expanded or shrunk what constitutes as fair. I then grouped similar cases together and formulated a guideline based on the rulings to apply to YouTube. These guidelines are based on the rulings of the case law and the precedent that these cases would set if any more fair use issues went to court.

\section{Results}

From the court cases and copyright law, I was able to determine standards for what is and is not considered fair use on YouTube based on previous court decisions. From copyright law, use for the purpose of education, criticism, or review is considered to be fair use based on the Copyright Act of 1976, 17 U.S.C. $§$ Section 107 (1976). From the court cases I researched I was able to pull out the rulings and apply them to the copyright system on YouTube in relation to common copyright issues on the site. From the ruling in Hosseinzadeh v. Klein (2017), it has been decided that, in most cases, when using content in a reaction video, if there is significant commentary in a way that shifts the focus away from the copyrighted content and instead focuses largely on the input of the creator, then the use qualifies as fair. For example the YouTube video The Big, the BOLD, the Beautiful contains a reaction to a video uploaded by Hosseinzadeh with frequent interruptions in order to provide humorous commentary making fun of the original creator. Because the commentary interrupted the video and shifted the focus away from the copyrighted content to the commentator, it is considered to be transformative and falls under fair use (Hosseinzadeh v. Klein). If the content is used for a purpose other than what was intended, it is also considered fair use. The cases SOFA Entertainment, Inc. v. Dodger Productions, Inc., (2013) and Monster Communications, Inc. v. Turner Broadcasting Sys. Inc. (1996) both involved documentaries including clips of previously copyrighted productions and used them for documentary purposes. Because the purpose of the content was changed from entertainment to historical in both cases, as well as the fact that only a small portion was used, the use was considered fair. If the video contains content for the purpose of parody, the specific parts of the content that are being satirized are considered to be fair use under the pretenses of Campbell v. Acuff-Rose Music, Inc. (1994). Generally, if the content does not serve as the main focus of the video and does not harm the market of the original content then it is likely to be considered fair use as found in Italian Book Corp., v. American Broadcasting Co. (1978). This case had a news station recording a parade in Little Italy with part of the program recording a band playing a copyrighted song; the case decided this was fair use.

Determining cases of copyright infringement can also be determined from the copyright law. Content that uses copyrighted work without adequate commentary is not considered to be fair use as described in Roy Export Co. Estab. of Vaduz v. Columbia Broadcasting Sys., Inc. (1982) where a montage of Charlie Chaplin's work was shown after his death. If the content is used as a supplement to support a topic being discussed, but is not actually being criticized or commentated upon, it is not fair use as found in Dlugolecki v. Poppel (2019) when a news station used Megahn Markel's yearbook pictures when discussing her engagement to Prince Harry. Because the pictures were simply being used for their intended purpose without any transformative nature, the use violated copyright law. If copyrighted material is found in the background of a video without any commentary regarding the piece, it is also not fair use according to the decision in Ringgold v. Black Entertainment Television, Inc. (1997) when a copyrighted artwork was used in the set design of a television show. This decision would also likely be applied to music used in the background of videos. If copyrighted content is posted publicly on other platforms, the content is not automatically 
available for creators to use because of the decision in McGucken v. Newsweek LLC (2020) when a website took a picture off of an Instagram page to promote their article without a license.

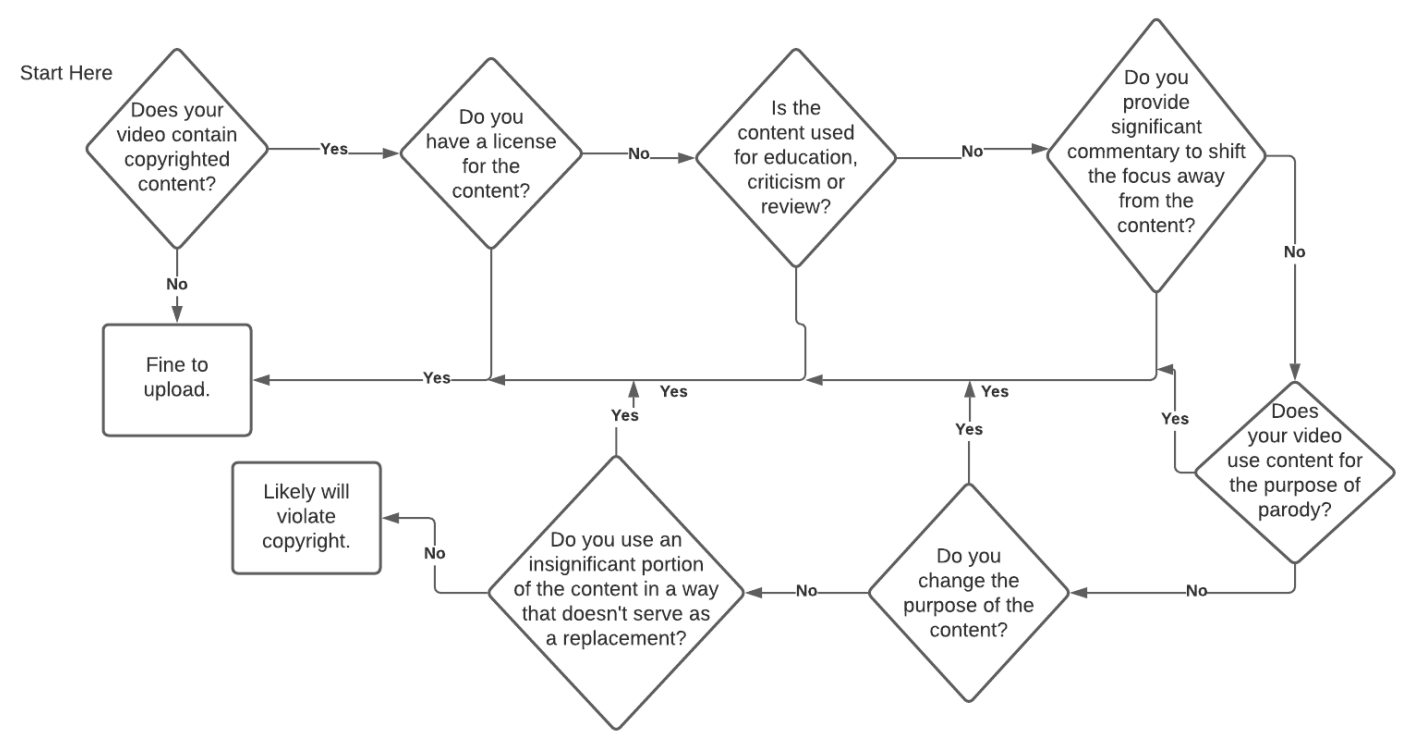

Figure 1. The decisions of the cases have been assembled into a flowchart that provides yes or no questions that can be answered to determine if a video will violate copyright law if uploaded. Users would start in the upper, left corner and answer successive questions until reaching "Fine to upload" or "Likely will violate copyright."

This flowchart is a comprehensive summary of the results of my findings, providing content creators with an easy-tofollow system to accurately assess whether their video will infringe on copyright or will be considered fair use under legal precedent. Obviously, this simple flow chart is not universally foolproof, but it can serve as a good example and baseline for what does and does not constitute fair use.

The decisions of the court cases can be applied, as a result of my findings, to YouTube by ultimately determining what should and should not be fair use on the site. A video that includes copyrighted content in a way that is educational and only uses enough of that material to adequately teach can be found in Film Theory's Film Theory: Kung Fu Panda, The REAL Reason Po is the Chosen One!. The video only contains enough of the copyrighted content from Kung Fu Panda in order to teach, protecting it under copyright law. An example of a piece of educational content that would cross the line established by Roy Export Co. Estab. of Vaduz v. Columbia Broadcasting Sys., Inc. would be Nerdstalgic's How This Became The WORST Episode Of The Office. A significant portion of the video uses copyright content from The Office for the purpose of education; however, a large abundance of copyrighted material is used as B-roll and is used as a supplement to make the video more interesting but does not actively transform the purpose of the work and is not fair use. The situation where only a small part of the copyrighted content is used in a way that changes the purpose can be seen within How 'I Spy' Books Are Made from Art Insider. The video is about the photographer behind the 'I Spy' books and uses many images from the books. What makes the use fair is that the purpose of the images has changed; they go from simply being search and find games into a portrayal of the hard work Walter Wick puts into them, and it is this change that makes the video transformative and fair use based on the precedent set by SOFA Entertainment, Inc. v. Dodger Productions, Inc.. The subtle differences between what is fair and what is not is better defined through specific examples found on YouTube to better help creators understand what is and is not allowed on YouTube.

Copyrighted content in the background of a video, constitutes another important standard that can be related back to YouTube. For example, THE END OF THE RETROSPECTIVE... by TheSmithPlays includes album artwork 
in the background of his video which would violate copyright based on Ringgold v. Black Entertainment Television, Inc.. The use of music in the background of the video with no commentary would also be considered copyright infringement based on the same case. Dissimilarly, the use of copyrighted music in the background for parody like in the video Drake - God's Plan (Fortnite Battle Royale Parody) is allowed based on Campbell v. Acuff-Rose Music, Inc. that determined use for parody to be considered transformative. The bright line differences between fair use and not are a lot easier to see and do not necessarily require further defining, but the subtle differences in defining fair use like discussed above will be greatly helped by these examples.

\section{Discussion}

This content analysis provides additional clarity to define bright line standards for fair use on YouTube. The general guidelines set by the research may help better implement solutions to allow greater protection for fair use on YouTube. Before this study there was minimal guidance to what falls under fair use, and many saw it as the "wild west" with many different interpretations on what was acceptable and what would violate copyright. By looking at the case law surrounding fair use on YouTube, there can now be proper guidelines to follow set by precedent of law, the ultimate solution established as a result of my findings.

With these further guidelines of what is and is not allowed based on precedent, further programs might be able to be implemented to solve the Content ID issue. If the guidelines provided could somehow be embedded into Content ID, so that it is able to take into account fair use when flagging, as Bartholomew suggested, then there would be far less problems on YouTube regarding copyright. Content ID's inability to detect fair use is a large problem due to exploitation from large copyright holders which would be eliminated by implementing the guidelines into Content ID. The developed guidelines could further be used for educational use for creators like Solomon has described. If creators can use the guidelines to determine whether or not their video is fair use, there will be less confusion on the creator's side in discussing why their video got claimed as well as making it easier for creators to identify copyright violations in their videos and make the necessary changes to their videos before uploading to ensure their use is fair. The educational aspect of the guidelines would not solve all of the issues caused by Content ID because many fair use videos will still be flagged, but the guidelines may help creators counter-claim the videos in order to get the revenue that is rightfully theirs.

Going into the study, it was known that the results of the study would not provide a clear-cut solution for the problems of copyright on YouTube, but the results of the study make it much clearer when it comes to defining what is and isn't fair use. There is so much confusion around copyright, and the lack of bright line standards does not mitigate these issues. After a content analysis of the case law and applying the decisions of the cases into YouTube's bubble of issues, the dull line of the difference between fair use and not becomes a lot clearer. This is a necessary step in helping to determine the next route for both parties to take in solving the problem of Content ID and fair use on YouTube.

Before the study, I was going to focus simply on court cases that related only to fair use on YouTube, but after searching through many court case databases, it was clear that there would not be enough court cases related to copyrighted content on YouTube. Because of this fact, I instead chose to look for fair use disputes on all media platforms and relate the decisions of the court cases back to YouTube. This decision is justified because media platforms such as television have very similar issues to YouTube regarding copyright making court decisions regarding either applicable to both. The only real difference between various media platforms is the ease of showing and uploading content on each platform. The average individual cannot put content on television; instead, content intended for television normally must go through multiple steps and checks, and ultimately there are fewer problems with copyrighted content being directly shown on the platform because of the extensive process to put content on television. A large amount of the grey area surrounding what is and is not fair remains the same across platforms and as a result remains relevant to the research. The decision to use court cases from other media in the content analysis provides a 
larger pool of court cases to review and does not vastly change the results of the study as the media platforms produce very similar content.

\section{Limitations}

My limitations have shaped my study greatly as I originally planned to use the Delphi Method to get expert advice on potential solutions to the Content ID issue; however, I was unable to get enough experts to participate in the study so instead I pursued a content analysis approach.

After deciding to pursue a content analysis, one of the biggest limitations when conducting the research was that the only available content to discuss was court cases, meaning that I could only analyze scenarios that went to court. Many fair use and copyright issues are settled outside of court, but content available to me for analysis was restricted to court cases on public record. This ended up reducing the number of potential court cases available for use in my content analysis and therefore made it more difficult to create bright-line guidelines for all situations.

Another limitation was that the very nature of fair use is circumstantial. Creators using these guidelines to base their work on could still be taken to court and have the judge decide that the use is not fair even if the content used would be considered fair use by the guidelines developed in the research. This creates a further problem because situations that are very unclear on the legality of the use of a copyrighted work would be the least likely to have an equivalent or relevant case in the case law. Many of the cases had rulings that claimed that all use of a similar nature is not necessarily fair use making implementing these cases into guidelines more difficult.

The use of the court cases did have a significant impact on my guidelines because of variation in the court system. Because the court cases were decided by different judges, they could all have had varying opinions on the interpretation of copyright law which would influence their court decision. The reliance on the subjectivity of judges is not an overwhelmingly large factor in the results of the study, but it does make the creation of stricter guidelines less feasible.

Despite the limitations, the guidelines set in the research will still be beneficial for creators to understand what has previously been decided in court when deciding whether or not to use copyrighted material in a specific way within their videos.

\section{Conclusion}

Through looking at the case law, it is clear that there is a strict legal precedent on using copyrighted work and this needs to be better conveyed to creators on YouTube. There are so many creators on YouTube that do not understand that most use of copyrighted content is not appropriate to use. Because it is so easy for creators on the internet to find and use copyrighted content for their videos, many forget that there are rules that need to be followed and limitations are in place to protect the copyrights of large corporations just as the small creators have their own content protected under the same laws. Through looking at the case law and interpreting the cases in a way that any creator can understand, there can be a lot less confusion over copyright in the future.

The main question when coming into the research was where the line is drawn when it comes to copyright. As discussed earlier, it is difficult to make hard and fast rules when determining fair use, as every case is so specific, the results of the study come short when looking at where the specific line is. The court case discussion makes seeing what is and is not fair use a little bit clearer, but overall there are no specific rules that can be adhered to on YouTube but instead flexible guidelines, making it more complicated for a creator. Creators may look at the guidelines, defined by my research and think their video may be fair use because it checks all the boxes of the guidelines, but if the specific video infringed in a very specific way not accounted for, it could go to court and be determined not fair use. 


\section{Future Direction}

In continuing the research, every day more cases are determined in court in which fair use may become clearer. The more cases decided, the more specific the guidelines can become. This will simplify the guidelines, making it easier for creators to follow. In the context of continuing research, YouTube is constantly trying to help creators battle copyright claims while also avoiding being sued. Because YouTube is constantly changing, a change to how Content ID works could solve the problems present or create entirely new problems in an instant.

Even though the future of fair use on YouTube is uncertain, my findings are beneficial to helping creators now. It does not seem plausible for the guidelines present to be integrated into an automated system like Content ID, and the main problem with fair use on YouTube now is the automated system, so the integration into a system such as that does not seem to be the most logical step. The use of the guidelines for educating creators would be a simpler implication for the research provided. If content creators would be able to compare their videos to the guidelines, they would be able to determine if they will be using content as fair use. The implications of my research could also be useful in furthering the guidelines in a way reflective of my method or attempt to apply them to alternative platforms. Content ID on YouTube is an astoundingly large issue that affects a large amount of content creators. Corporations have been exploiting their copyrighted material in a way that harms the creative community. Through creating further, easy to understand, guidelines for determining fair use, we come one step closer to creating a system that both protects copyrighted works and the rights of creators.

\section{Acknowledgments}

I would like to thank my advisor John Murnan for serving as a guide through the research process. I also would like to express gratitude to my research class for helping me with peer edits and presentation help throughout the research process. Additionally, I would also like to thank the US Copyright Office for aggregating fair use cases and Harvard's Library Innovation Lab for providing free access to court cases on case.law.

\section{References}

Bartholomew, T. (2015). The death of fair use in cyberspace: YouTube and the problem with Content ID. Duke Law and Technology Review, 13(1), 66-88.

Brown, B. (2008). Fortifying the safe harbors: Reevaluating the DMCA in a web 2.0 world. Berkeley Technology Law Journal, 23(473), 437-468.

Campbell v. Acuff-Rose Music, Inc., 510 U.S. 569, 127 L. Ed. 2d 500, 114 S. Ct. 1164 (1994)

Copyright Act of 1976, 17 U.S.C. § Section 107 (1976)

Guzman, F. (2015). The tension between derivative works online protected by fair use and the takedown provisions of the Online Copyright Infringement Liability Limitation Act. Northwestern Journal of Technology and Intellectual Property, 13(2), 180-196.

Hosseinzadeh v. Klein, 276 F. Supp. 3d 34 (2017)

Marfo, N. (2019). Playing fair: YouTube, Nintendo, and the lost balance of online fair use. Brooklyn Journal of Corporate, Financial \& Commercial Law, 13(1), 456-489.

McGucken v. Newsweek LLC 19 Civ. 9617 (KPF), 2020 U.S. Dist. LEXIS 96126 (S.D.N.Y. June 1, 2020)

Monster Communications, Inc. v. Turner Broadcasting Sys. Inc., 935 F.Supp. 490 (S.D. N.Y., 1996)

Ringgold v. Black Entertainment Television, Inc., 126 F.3d 70 (2d Cir. 1997)

Roy Export Co. Estab. of Vaduz v. Columbia Broadcasting Sys., Inc., 672 F.2d 1095, 1100 (2d Cir. 1982)

SOFA Entertainment, Inc. v. Dodger Productions, Inc., No. 2:08-cv-02616 (9th Cir. Mar. 11, 2013) 
Solomon, Leron (2015) "Fair Users or Content Abusers? The Automatic Flagging of Non-Infringing Videos by Content ID on YouTube," Hofstra Law Review: Vol. 44: Iss. 1, Article 8.

Teller v. Dogge, 8 F. Supp. 3d 1228 (2014)

Vogele, J. (2017). Where's the fair use? The takedown of let's play and reaction videos on YouTube and the need for comprehensive DMCA reform. Touro Law Review, 33(2), 589-632. 